\title{
Fitoremediasi Logam Aluminium (Al) Pada Lumpur Instalasi Pengolahan Air Menggunakan Tanaman Melati Air (Echinodorus palaefolius)
}

\author{
Monik Kasman*, Anggrika Riyanti, dan Catur Endah Kartikawati \\ Program Studi Teknik Lingkungan Universitas Batanghari \\ *e-mail : monik.kasman@unbari.ac.id
}

\begin{abstract}
ABSTRAK
Air bersih sebagai kebutuhan dasar diproduksi oleh Perusahaan Daerah Air Minum (PDAM) dan hasil samping produksi tersebut adalah berupa lumpur. Lumpur PDAM mengandung logam $\mathrm{Al}$ dalam bentuk $\mathrm{Al}(\mathrm{OH})_{3}$ yang berpotensi sebagai pencemar jika langsung dibuang ke lingkungan. Penelitian ini bertujuan untuk mengetahui efisiensi penyisihan parameter logam Al pada limbah lumpur PDAM melalui fitoremediasi dengan menggunakan tanaman melati air dan untuk mengetahui serapan logam Al yang terakumulasi pada akar tanaman melati air pada bak fitoremediasi I (tanpa media) dan bak fitoremediasi II (dengan media kerikil dan tanah humus) Pengambilan sampel lumpur dilakukan secara langsung pada pipa outlet Sludge Drying Bed (SDB) PDAM IPA Tanjung Sari. Selanjutnya dilakukan proses fitoremediasi untuk mereduksi kandungan logam Al pada lumpur PDAM dengan menggunakan tanaman melati air. Analisis konsentrasi logam Al dilakukan pada waktu tinggal 3, 5, 7, 9 dan 11 hari dan analisis serapan logam Al pada bagian akar tanaman melati air dilakukan setelah proses fitoremediasi pada hari ke-11. Hasil penelitian menunjukkan pada waktu tinggal 3, 5, 7, 9 dan 11 hari tingkat efisiensi penyisihan konsentrasi logam Al pada bak fitoremediasi I secara berurutan yaitu 46\%; $62 \% ; 72 \% ; 80 \%$; dan $83 \%$, sedangkan pada bak fitoremediasi II yaitu 50\%; 67\%; 75\%; 81\%; dan 86\%. Konsentrasi serapan logam Al pada akar tanaman melati air pada bak fitoremediasi I dan bak fitoremediasi II yaitu 898,10 mg/l dan 302,42 mg/l. Tingginya serapan Al pada bak fitoremediasi I dikarenakan tidak adanya media tanam sehingga penyerapan logam Al terjadi lebih optimal namun tanaman mengalami daya regenerasi yang rendah. Sedangkan pada bak fitoremediasi II yang memiliki media tanam berupa kerikil dan tanah humus dapat membentuk zona rizosfer yang kaya oksigen dan mikroorganisme sehingga tanaman memiliki regenerasi yang lebih tinggi.
\end{abstract}

Kata kunci : Lumpur PDAM; Fitoremediasi; Logam aluminium

\begin{abstract}
Clean water as basic need produced by the Regional Water Company (PDAM) and the by-product of this production was in the form of sludge. PDAM sludge contain Aluminium in the form of $\mathrm{Al}(\mathrm{OH})_{3}$ with the potential pollution if thrown into environment. This research aims to determine the efficiency of removal of Al metal on PDAM sludge through phytoremediation by using jasmine water plants and to determine the absorption of Al metal that accumulates in the roots of water jasmine plants in phytoremediation $I$ (without media) and phytoremediation II (with gravel and humus soil). Sludge sample was carried out directly on the outlet sludge drying bed PDAM Water Treatment Plant (IPA) Tanjung Sari. The phytoremediation process is then carried out to reducted Al metal content in the sludge by using water jasmine plants. Furthermore, Al metal concentrations were analyzed at 3, 5, 7, 9 and 11 days of contact and analysis of Al metal absorption on the roots of jasmine water plants was done after phytoremediation process in days-11. The result showed at the contact time 3, 5, 7, 9, and 11 day, the efficiency of Al metal concentration on the phytoremediation I in a sequence were 46\%; 62\%; 72\%; 80\%; and 83\%, while in phytoremediation II were $50 \%$; 67\%; $75 \%$; $81 \%$; and $86 \%$. The concentration of Al metal absorption on the roots of jasmine plant water at phytoremediation I and phytoremediation II are 898,10 $\mathrm{mg} / \mathrm{l}$ dan 302,42 mg/l. The high absorption in the phytoremediation I due to the absence of planting media so the metal occurs more optimal but they really experienced low power regeneration. While in phytoremediation II which has a growing media, formed a rizosfer zone which is rich in oxygen and microorganism so that the plant having a higher level of regeneration.
\end{abstract}

Keywords: PDAM Sludge; Phytoremediation; Aluminium metal

\section{Pendahuluan}

Sistem pengolahan air pada Instalasi Pengolahan Air (IPA) Tanjung Sari merupakan salah satu pengolahan air yang melayani kebutuhan air bagi masyarakat di Kota Jambi. IPA ini menggunakan pengolahan konvensional dengan sistem pengolahan lengkap mulai dari air baku, intake, koagulasi, flokulasi, sedimentasi, filtrasi, desinfeksi, dan reservoir. Pengolahan air pada IPA Tanjung Sari yang menghasilkan produk samping berupa lumpur yang berasal dari bak flokulasi, sedimentasi, dan filtrasi. Lumpur tersebut selanjutnya dialirkan menuju kolam lumpur (Sludge Drying Bed) untuk pengeringan tanpa proses pengolahan terlebih dahulu. Produksi lumpur di IPA Tanjung Sari dalam 1 hari sebesar $12 \mathrm{~m}^{3} /$ hari. Jumlah lumpur dapat bervariasi setiap hari berdasarkan debit air yang diolah dan konsentrasi kekeruhan air baku. 
Lumpur yang dihasilkan dari pengolahan air pada IPA mengandung logam $\mathrm{Al}$ dalam bentuk $\mathrm{Al}(\mathrm{OH})_{3}$ yang berpotensi sebagai pencemar jika langsung dibuang ke badan air. Kandungan logam Al pada lumpur ini berasal dari proses pembumbuhan koagulan pada proses koagulasi. Koagulan yang digunakan adalah jenis tawas atau alum dengan rumus kimia $\mathrm{Al}_{2}\left(\mathrm{SO}_{4}\right)_{3}$. Alum paling banyak digunakan untuk koagulan karena mudah didapat, mudah digunakan dan ekonomis harganya dibanding koagulan lain. Namun alum memiliki kelemahan yaitu menambah jumlah ion $\mathrm{Al}^{3+}$ kedalam air dan dapat menimbulkan pencemaran (Suherman, 2003).

Kandungan logam Al pada sampel limbah lumpur instalasi PDAM menunjukkan konsentrasi yang tinggi melebihi batas yang ditetapkan oleh Keputusan Menteri Kesehatan No. 492/Menkes/Per/IV/2010 yaitu sebesar 314,74 mg/l (Santriyana, 2013). Lumpur yang dihasilkan jika dibuang langsung ke sungai dan seringkali menimbulkan masalah karena akan mengakibatkan logam Al terakumulasi di perairan melalui proses rantai makanan. Logam Al yang berbahaya tersebut dapat berpindah lewat hewan air sampai manusia kembali (Setyono, 2008). Apabila logam Al tersebut terakumulasi di tubuh manusia akan menimbulkan gangguan kesehatan seperti gangguan pernapasan, dan jika terserap ke dalam kulit menyebabkan tersumbatnya pori-pori kulit sehingga kulit tidak bisa mengeluarkan racun secara alami (Singh, 2006).

Fitoremediasi merupakan salah satu upaya yang dapat dilakukan untuk menurunkan kandungan logam Al dalam limbah lumpur IPA. Proses ini memanfaatkan tumbuhan dan mikroorganisme untuk meminimalisasi dan mendetoksifikasi polutan, karena tanaman mempunyai kemampuan menyerap logam dan mineral yang tinggi atau sebagai fitoakumulator dan fitochelator. Metode fitoremediasi yang digunakan adalah dengan sistem lahan basah buatan (constructed wetland), dimana limbah lumpur dialirkan dalam reaktor yang ditanami tumbuhan yang berfungsi sebagai penyerap bahan pencemar dalam lumpur tersebut.

Tanaman yang telah digunakan untuk proses fitoremediasi logam antara lain Thlaspi calaminare (Zn), T. Caerulescens (Cd), Aeolanthus biformifolius $(\mathrm{Cu})$, Phylanthus serpentinus (Ni), Haumaniastrum roberti (Co), Astragalus racemosus (Se), Alyxia rubricaulis (Mn) (Wise, et. al., 2000). Tanaman melati air (Echinodorus palaefolius) dipilih sebagai tanaman fitoremediasi karena memiliki kemampuan untuk mengolah kandungan pencemar dalam air (Kasman, 2018; Santriyana, 2013). Struktur tanaman melati air yang memiliki akar serabut dan batang yang berongga besar mampu menyuplai oksigen ke akar dalam jumlah yang besar dan akar tanaman. Tanaman ini mampu menyerap kandungan Al pada limbah PDAM sebesar 96,46\% (Santriana, 2013).

Penelitian ini bertujuan untuk melihat efektifitas penyisihan parameter logam Al pada lumpur PDAM di IPA Tanjung Sari dengan memvariasikan media tanam dan wantu kontak.

\section{Metode Penelitian}

Penelitian ini merupakan penelitian eksperimen. Eksperimen dilakukan dengan 3 perlakuan, yaitu perbedaan pada media tanam lahan basah buatan. Perlakuan I yaitu bak fitoremediasi tanpa pengolahan (sebagai blanko). Perlakuan II, bak fitoremediasi dengan media tanam lumpur PDAM. Perlakuan III, bak fitoremediasi dengan media tanam tanah humus, kerikil, dan lumpur PDAM. Waktu tinggal limbah lumpur pada reaktor divariasikan yaitu 3, 5, 7, 9, dan 11 hari.

Sampel lumpur IPA diambil pada saluran inlet sludge drying bed pada 3 waktu pada pukul 05.00 WIB, 13.00 WIB dan 19.00 WIB. Kemudian dilakukan pengadukan lumpur agar homogen. Analisis konsentrasi Al dilakukan pada sampel awal dan sampel air hasil olahan pada masing-masing variasi waktu tinggal.

\subsection{Aklimatisasi}

Aklimatisasi tanaman dilakukan untuk pengadaptasian tanaman terhadap lingkungan baru. Aklimatisasi tanaman dilakukan sebelum dilakukan eksperimen dengan merendam dan membiarkan tanaman selama 3 (tiga) hari dalam sampel limbah lumpur untuk mengkondisikan dan memastikan tanaman tidak layu ataupun mati. Setelah itu tanaman dinetralkan kembali dengan air bersih selama 1 (satu) hari lalu kemudian ditanam pada media yang telah disediakan untuk eksperimen

\subsection{Desain Reaktor}

Reaktor didesain menjadi 11 reaktor yang meliputi 1 reaktor kontrol, 5 reaktor fitoremediasi I dan 5 reaktor fitoremediasi II. Pada reaktor pertama adalah bak kontrol yang terdiri dari ember plastik bervolume 5,5 liter dengan dimensi bak reaktor yaitu tinggi $35 \mathrm{~cm}$ dan diameter $25 \mathrm{~cm}$. Pada bak kontrol tidak dilakukan proses fitoremediasi. Desain reaktor dapat dilihat pada Gambar 1 .

Reaktor fiteoremediasi I dibuat sebanyak 5 bak sesuai dengan variasi waktu tinggal yaitu 3,57,9, and 11 hari. Masing-masing bak diisi lumpur (tanpa media tanam) dan tanaman melati air, dengan umur tanaman pada tiap yaitu 1 bulan dan berat 300 gram.

Reaktor fiteoremediasi II dibuat sebanyak 5 bak sesuai dengan variasi waktu tinggal yang sama dengan bak fitoremediasi I. Perbedaannya adalah pada masingmasing bak diisi dengan media tanam berupa kerikil setinggi $3 \mathrm{~cm}$ pada lapisan bawah, tanah humus setinggi $5 \mathrm{~cm}$ pada lapisan kedua. Tanaman melati air ditanam pada media tersebut dan kemudian diisi dengan sampel lumpur. Umur tanaman yang digunakan pada tiap bak adalah 1 bulan dengan berat 300 gram.

Sampel air hasil pengolahan diambil pada tiap bak fitoremediasi I dan Bak fitoremediasi II sesuai variasi waktu tinggalnya dan dianalisis konsentrasi logam $\mathrm{Al}$ di Laboratorium Saraswanti Indo Genetech Bogor. Kemudian analisis dilakukan untuk melihat pengaruh waktu tinggal terhadap penurunan konsentrasi Al. 

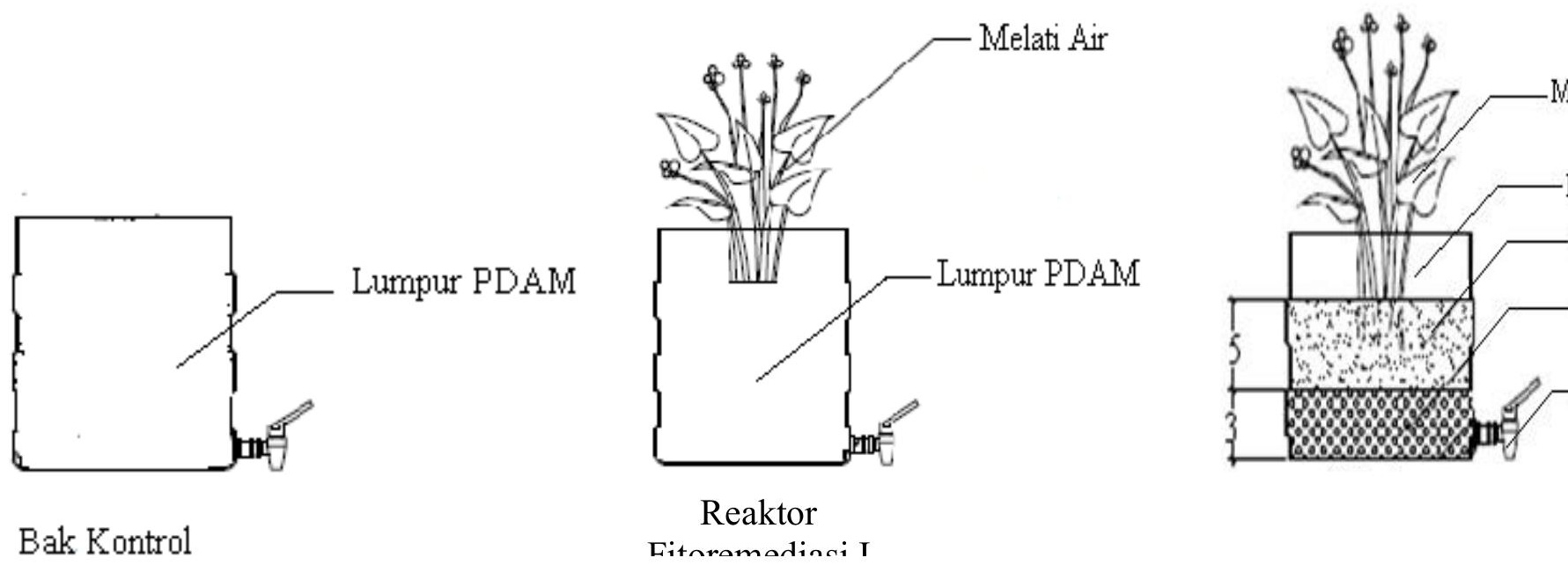

Gambar 1. Desain reaktor fitoremediasi

\section{Hasil dan Pembahasan}

\subsection{Karakteristik Lumpur IPA PDAM Tanjung Sari}

Karakteristik lumpur sangat dipengaruhi oleh beberapa faktor, antara lain sumber lumpur, proses di IPA, sifat fisik dan komposisi kimia. Produksi lumpur di PDAM Tanjung Sari dalam 1 hari sebesar $12 \mathrm{~m} 3 /$ hari. Sampel lumpur IPA yang diambil secara fisik berwarna coklat pekat dan lumpur tersebut sifatnya diskrit maupun flokulen. Diskrit yaitu lumpur yang butirbutirannya terpisah tanpa koagulan, mayoritas lumpur ini mengandung pasir, grit, dan pecahan kerikil berukuran kecil. Lumpur yang berupa flokulen yaitu didominasi oleh koloid.

Hasil analisis sampel lumpur awal memiliki konsentrasi $\mathrm{Al}$ sebesar 58,29 mg/l dengan ph 5,76 yang bersifat asam dan suhu $28,7^{\circ} \mathrm{C}$

\subsection{Analisis Waktu Tinggal terhadap Konsentrasi Logam Al}

Hasil penelitian (Gambar 2) menunjukkan bahwa penambahan waktu tinggal mempengaruhi penurunan konsentrasi logam Al, dimana konsentrasi logam Al terendah untuk kedua reaktor (fitoremediasi I dan fitoremediasi II) terjadi pada waktu tinggal 11 hari. Laju penurunan cukup tinggi terjadi pada hari ke-3 pada kedua reaktor, yaitu sebesar $26,79 \mathrm{mg} / \mathrm{l}$ pada fitoremediasi I dan $29,18 \mathrm{mg} / \mathrm{l}$ pada firemediasi II.

Kemudian laju penurunan menjadi stabil pada hari ke-5 sampai hari ke-9 dan lebih rendah paa hari ke-11. Terjadinya penurunan tajam pada awal percobaan diduga dipengaruhi oleh kandungan nutrien yang dibutuhkan untuk pertumbuhan mikroorganisme cukup melimpah, sehingga akan terjadi fase pertumbuhan dipercepat (exponential growth phase).

Hari ke-7, bak fitoremediasi I dan bak fitoremediasi II telah mencapai titik optimal yaitu 6,02 $\mathrm{mg} / \mathrm{l}$ dan 4,64 mg/l. Hal ini dikarenakan nutrient yang dibutuhkan oleh mikroorganisme telah berhasil terserap oleh akar tanaman melati air sehingga tanaman melati air dapat mencapai titik optimal. Kondisi ini menyebabkan terjadi keseimbangan antara pertumbuhan dan kematian mikroorganisme yang sering disebut sebagai stationary phase.

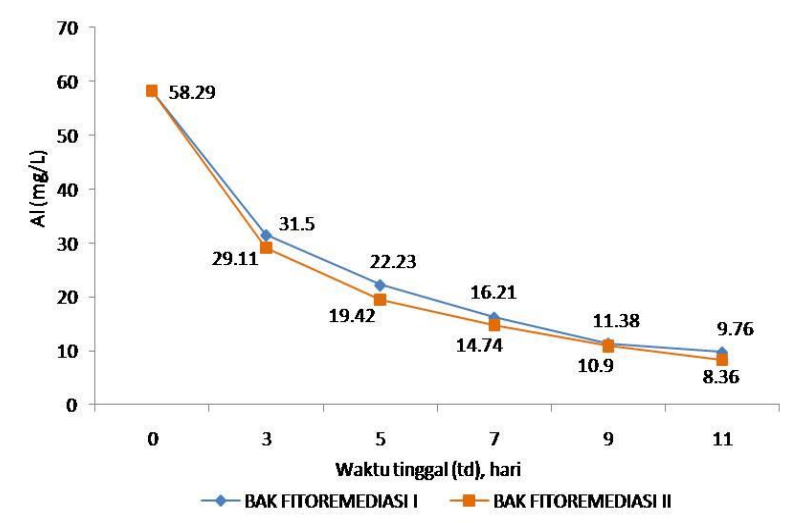

Gambar 2. Pengaruh Waktu Tinggal (td) dan Media Terhadap Konsentrasi Logam Al

Gambar 3 menunjukkan efisiensi penyisihan konsentrasi logam Al pada bak fitoremediasi I dan II. Penyisihan pada hari ke-3 telah mencapai $46 \%$ pada fitoremediasi I dan $50 \%$ pada fitoremediasi II. 
Kemudian penyisihan logam Al terbesar terjadi pada hari ke-11 sebesar $83 \%$ pada fitoremediasi I dan $88 \%$ pada fitoremediasi II.

Pada penelitian Santriyana (2013), efektifitas penyerapan logam Al mencapai 96,46\% dengan waktu tinggal 70 hari. Dengan demikian proses fitoremediasi yang dilakukan dalam penelitian ini sudah cukup baik karena tanaman melati air mampu menyisihkan konsentrasi logam Al sebesar $86 \%$ dalam waktu 11 hari.

Hasil penelitian menunjukkan penurunan konsentrasi Al yang lebih baik terjadi pada reaktor fitoremediasi II, dimana media tanam ternyata juga ikut berperan dalam membantu penyisihan konsentrasi logam Al dalam limbah lumpur. Hal ini terjadi karena tanaman memiliki mekanisme tersendiri untuk menstimulasi biovailabilitas ion-ion logam pada lingkungan rhizosfernya agar dapat diserap melalui akar. Proses masuknya logam Al ke dalam akar tanaman dapat melalui jalur apoplas korteks akar secara transport pasif dan kemudian ditransportkan melalui jalur simplasmik ke organ lain seperti batang dan daun. Apoplas merupakan jaringan berongga yang mengandung banyak cairan yang terdapat diantara lingkungan rhizosfer dan membran sel dari korteks akar dan jaringan pembuluh yang mengandung banyak senyawa bermuatan negatif yang berperan sebagai kompleks pengikat kation dan sebagai pelepasan anion.

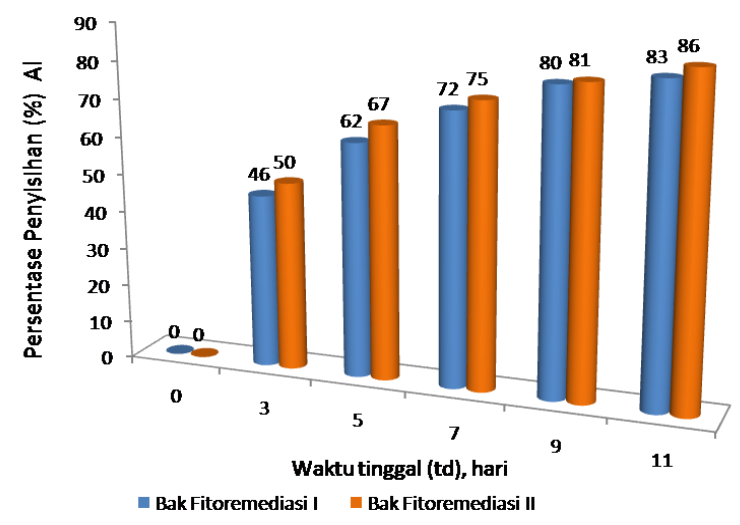

Gambar 3. Pengaruh Waktu Tinggal (td) Terhadap Efisiensi Penyisihan Konsentrasi Logam Al

Seperti halnya pada bak fitoremediasi II, lingkungan rhizosfer yang rimbun terbentuk karena adanya media tanaman kerikil dan tanah humus sehingga organisme pengurai seperti bakteri aerob dapat hidup dengan baik dalam lingkungan berkondisi ini
(Supradata, 2005). Hal ini menyebabkan mekanisme penyerapan logam Al menjadi lebih optimal dibandingkan bak fitoremediasi I. Selain itu, daya tahan tanaman terhadap limbah lebih baik terjadi pada proses fitoremediasi II dan mempunyai daya regenerasi yang lebih tinggi dibandingkan pada bak fitoremediasi I.

\section{Kesimpulan}

Fitoremediasi dengan sistem lahan basah buatan (construted wetland) dengan menggunakan tanaman melati air dinilai cukup baik dalam menyisihkan logam Al dalam limbah lumpur IPA. Hasil penelitian menunjukkan efisiensi penyisihan logam $\mathrm{Al}$ yang cukup tinggi mencapai $83 \%$ dengan konsentrasi Al 9,76 mg/l pada proses fitoremediasi tanpa media tanam, dan $86 \%$ pada proses dengan media tanam dengan penurunan konsentrasi Al 8,36 mg/l. Proses fitoremediasi dengan media tanam memiliki kemampuan penyisihan logam Al yang lebih baik karena terbentuknya zona rhizosfer pada akar tanaman yang mendukung zona hidup mikroorganisme pengurai sehingga dapat mendegradasi limbah lebih optimal.

\section{Daftar Pustaka}

Kasman, M. et.al. (2018). Reduksi pencemar limbah cair industri tahu dengan tumbuhan melati air (Echinodorus palaefolius) dalam sistem kombinasi constructed wetland dan filtrasi. Jurnal Litbang Industri, 8(1): 39-46.

Santriyana, D.D. (2013). Eksplorasi Tanaman Fitoremediasi Aluminium (Al) yang Ditumbuhkan pada Limbah IPA PDAM Tirta Khatulistiwa Kota Pontianak. Penelitian, Pontianak : Ilmu Tanah Tanjungpura.

Singh, Rajender. 2006. Introduction to Basic Manufacturing Processes and Workshop Technology. New Delhi: New Age International.

Suherman, B. (2003). "Upaya Minimalisasi Kebutuhan Koagulan di PDAM" Seminar Nasional Teknik Kimia Indonesia Bersama dengan Seminar Nasional Soehadi Reksowardjojo. Intitut Teknologi Bandung dan Fundamental \& Aplikasi Teknik Kimia 2003 Institut Teknologi Sepuluh Nopember Surabaya, Yogyakarta tanggal 16 - 17 September 2003.

Supradata. (2005). Pengolahan Limbah Domestik Menggunakan Tanaman Hias Cyperus alternifolius L. dalam Sistem Lahan Basah Buatan Aliran Bawah Permukaan (ssf-wetlands). Tesis. Semarang : Magister Ilmu Lingkungan UNDIP.

Wise D.L., Trantolo D.J., Cichon E., Inyang H.I. AND Stottmeister U. (Eds.). (2000). Bioremediation of Cotaminated Soils. Marcek Dekker: New York, Basel. 